\title{
OS CARCHARHINIFORMES (CHONDRICHTHYES, NEOSELACHII) DA BACIA DE ALVALADE (PORTUGAL)
}

Trabajo presentado a las XVIII Jornadas de Paleontología y

II Congreso Ibérico de Paleontología

Universidad de Salamanca

Salamanca, 24-29 de Septiembre de 2002

\author{
Miguel Telles ANTUNES e Ausenda Cáceres \\ $B A L B I N O^{2}$ \\ ${ }^{1}$ Academia das Ciências de Lisboa. \\ Centro de Estudos geológicos da Universidade Nova de Lisboa, Quinta da \\ Torre,2825-114 Caparica, Portugal. E-mail: mta@mail.fct.unl.pt / \\ ip241333@ip.pt \\ ${ }^{2}$ Departamento de Geociências, Universidade de Évora, Apartado 94, 7002- \\ 554 Évora, Portugal. Centro de Estudos Geológicos da Universidade Nova \\ de Lisboa. E-mail: acaceres@uevora.pt.
}

Antunes, M.T. e Balbino, A.C. 2004. Os carcharhiniformes (Chondrichthyes, Neoselachii) da Bacia de Alvalade (Portugal). [The Carcharhiniformes (Chondrichthyes, Neoselachii) from the Alvalade Basin (Portugal).] Revista Española de Paleontología, 19 (1), 73-92. ISSN 0213-6937.

\begin{abstract}
The uppermost Miocene, Esbarrondadoiro Formation (Alvalade basin, Portugal) yielded more than 10 thousand Selachian teeth at Santa Margarida, Esbarrondadoiro and Vale de Zebro outcrops. Forty-five taxa were identified belonging to the orders Hexanchiformes, Squaliformes, Lamniformes, Carcharhiniformes, Torpediniformes and Myliobatiformes.

The Carcharhiniformes make up about $40 \%$ of the selachian fauna that has been identified in the studied area. The families Scyliorhinidae, Triakidae, Hemigaleidae, Carcharhinidae and Sphyrnidae, and fifteen species are recognized.

The distribution of the Carcharhiniformes by the Santa Margarida, Esbarrondadoiro and Vale de Zebro localities is shown (Table 1). The quantitative taxa distribution among these localities is very unequal. The predominant forms are Premontreia (Oxyscyllium) cf. dachiardi, Mustelus sp., Paragaleus antunesi, and especially Carcharhinus cf. perezi.

The rarity of the tiger-shark, Galeocerdo, is interesting. Its decline in european seas was then obvious. It represents the last occurrence in the Miocene of Portugal.

The different distribution of the Carcharhiniformes (as well as that of the other orders) by the three sites points out to distinct environments in the corresponding areas: Esbarrondadoiro indicates relatively deeper, rather still waters; Santa Margarida represents a very littoral area and rough waters; while Vale de Zebro was a (probably inner) part of a gulf with muddy bottoms.

Stenotherm, termophilous forms that were common or plentiful before are absent. The near absence of Galeocerdo gives a similar indication, as well as the total lack of termophilous crocodilians that were common until the Middle Miocene and still were represented in the Tortonian.

At the Alvalade Basin localities there are several "temperate" elements that still are present in Portuguese waters. However the high frequence of Carcharhinus, a genus that is scarce at present off Portugal, indicates waters somewhat warmer than today's but less warm than during Tortonian times. This is corroborated by the large number of Dasyatis species and the rarity of Raja. We may conclude that moderately warm (less warm than during Tortonian, but warmer than today's) waters predominated in the Alvalade Basin close by the end of Miocene.

The scarcity of pelagic forms and especially of the larger pelagic predators points out to a quite narrow gulf and not to an open Atlantic front. The faunal differences between the Tortonian near Lisbon and the Messinian of the Alvalade Basin also indicate a rather confined gulf here in contrast with the open sea environments recognized for the Tortonian near Lisbon.

Among the modernity signs of the Alvalade Basin selachian fauna in comparison with earlier Miocene ones are the highly developed characters of Galeocerdo and Carcharhinus.
\end{abstract}

Key words: Selachians, Carcharhiniformes, Alvalade Basin, Portugal, uppermost Miocene. 


\section{RESUMO}

As jazidas de Santa Margarida, Esbarrondadoiro e Vale de Zebro, da Formação de Esbarrondadoiro (Miocénico terminal) da Bacia de Alvalade - Portugal, proporcionaram a recolha de cerca de 10.000 dentes de seláceos, em associação bastante rica. Foram identificados e descritos quarenta e cinco táxones pertencentes às ordens Hexanchiformes, Squaliformes, Lamniformes, Carcharhiniformes, Torpediniformes e Myliobatiformes.

Os Carcharhiniformes representam cerca de $40 \%$ dos táxones identificados. Estão representadas as famílias Scyliorhinidae, Triakidae, Hemigaleidae, Carcharhinidae e Sphyrnidae, com quinze espécies.

A distribuição dos Carcharhiniformes pelas jazidas de Santa Margarida, Esbarrondadoiro e Vale de Zebro, é a que se mostra na tabela 1. A repartição quantitativa dos táxones é muito desigual. Predomínam Premontreia (Oxyscyllium) cf. dachiardi, Mustelus sp., Paragaleus antunesi, e, sobretudo, Carcharhinus cf. perezi.

É interessante a raridade do tubarão-tigre, Galeocerdo, cuja decadência em mares europeus era já evidente É a última ocorrência conhecida no Miocénico de Portugal.

A repartição diferente dos Carcharhiniformes (assim como a das outras ordens) nas três jazidas aponta para áreas distintas: - Esbarrondadoiro indica meio relativamente mais profundo e águas pouco agitadas; - Santa Margarida corresponde a uma área litoral e a mar agitado; - Vale de Zebro, a parte interior de um golfo com fundos vasosos.

Verificam-se ausências de formas estenotérmicas termófilas, antes comuns, algumas abundantes. A quase ausência de Galeocerdo, vai no mesmo sentido. Corrobora a interpretação a falta na Bacia de Alvalade de restos dos crocodilos termófilos, comuns até o início do Miocénico médio e ainda representados no Tortoniano.

Há elementos predominantemente "temperados" em Alvalade, frequentes na actualidade, enquanto que a frequência de Carcharhinus aponta para águas algo mais quentes do que as dos nossos dias, embora menos do que em tempos do Tortoniano. Isto é corroborado pela abundância e variedade das espécies de Dasyatis e a raridade de Raja. Predominavam no final do Miocénico e na Bacia de Alvalade águas moderadamente quentes, menos do que no Tortoniano, mais do que na actualidade.

A escassez de fauna pelágica e dos maiores predadores pelágicos permite afirmar estarmos perante um golfo relativamente estreito e não de uma fachada atlântica aberta. A diferença de faunas entre o Tortoniano de Lisboa e o Messiniano de Alvalade apontam no mesmo sentido: meio confinado em Alvalade, contrastando com situação de mar aberto no Tortoniano de Lisboa.

Um carácter de modernidade, comparativamente a faunas miocénicas anteriores consiste no carácter muito evoluído do Galeocerdo e de Carcharhinus.

\section{Palavras-chave: Seláceos, Carcharhiniformes, Bacia de Alvalade, Portugal, Miocénico terminal.}

\section{INTRODUÇÃO}

No decurso do Miocénico diferenciaram-se, ou foram reactivadas bacias sedimentares na área hoje correspondente a Portugal. A mais importante é a do Baixo Tejo, que dá excelente testemunho de várias transgressões marinhas e de importantes modificações paleogeográficas. A Sul da Península de Setúbal ocorrem também depósitos marinhos que escassas faunas malacológicas apenas permitiam reportar ao Tortoniano, sem rigor. Na realidade, não há apenas um conjunto de sedimentos marinhos, confundidos embora numa só unidade. A situação evoluiu graças a algumas datações precisas a partir de faunas de pequenos mamíferos, cujos restos foram recolhidos nas mesmas camadas com fósseis marinhos. Assim, foi possível reconhecer que os depósitos de até as imediações de Alcácer do Sal, com destaque para a jazida de Cerrado da Pedra, datavam do final do Miocénico médio (Antunes e Mein, 1983), inserindo-se naturalmente na Bacia do Baixо Tejo.
Ainda mais para Sul, após uma separação constituída pelo horst de Valverde, outros depósitos marinhos correspondiam a uma bacia distinta, entretanto diferenciada, a qual também se não confunde com a moderna Bacia do Sado. Pesquisas em jazidas ricas de fauna ictiológica vieram a dar alguns elementos não marinhos, entre os quais um peixe de água doce, o último Characiforme europeu (Antunes et al., 1995), Trionyx, mastodontes e Hipparion (Alberdi et al., 1978), além de pequenos mamíferos que permitiram, pela primeira vez em Portugal, datar jazidas do Miocénico terminal, ca. de 5.5 Ma, atribuíveis ao Turoliano (em termos continentais; correspondendo sem rigor ao Messiniano marinho) (Antunes et al., 1986; Antunes e Mein, 1989, 1995) (fig. 1).

As jazidas fossíliferas (Santa Margarida, Esbarrondadoiro e Vale de Zebro) da Formação de Esbarrondadoiro, Bacia de Alvalade - Portugal (fig. 2), revelaram uma fauna de seláceos rica e variada, representada por cerca de 10.000 dentes. Oferece o interesse especial de ser a única ictiofauna do Miocénico terminal reconhecida em 


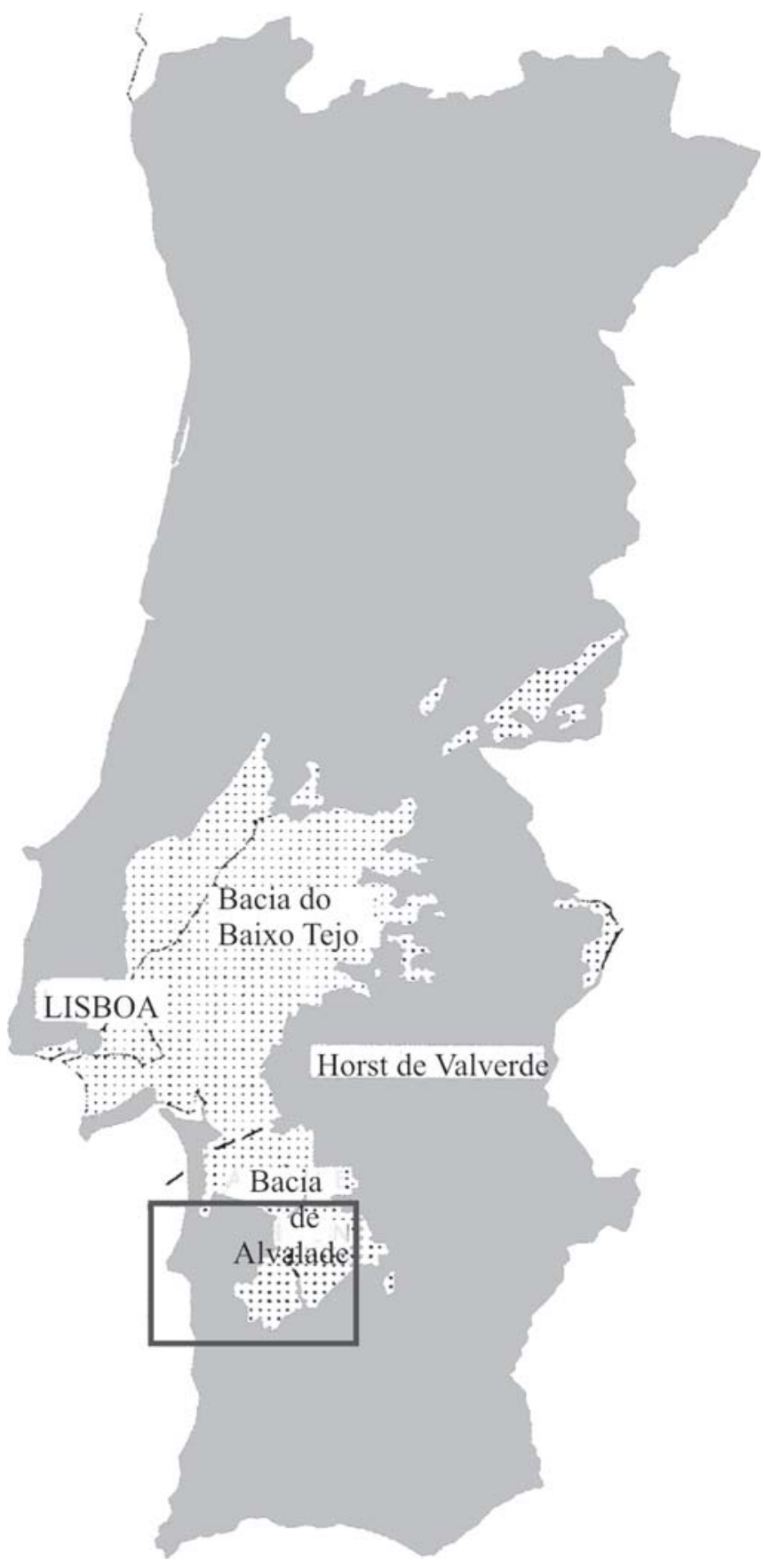

Figura 1. Mapa de Portugal mostrando a distribuição das Bacias do Baixo Tejo e de Alvalade. Área a ponteado: depósitos neogénicos.

Map of Portugal to show the location of the Lower Tagus and Alvalade basins. Area with points: Neogene deposits.
Portugal, diferente sob vários pontos de vista das que a antecedem. Para mais, são escassos os casos de faunas sincrónicas na Europa ocidental.

Foram identificados e descritos quarenta e cinco táxones pertencentes às ordens: Hexanchiformes, Squaliformes, Lamniformes, Carcharhiniformes, Torpediniformes e Myliobatiformes. Os Carcharhiniformes representam cerca de $40 \%$ do total dos táxones identificados na Bacia de Alvalade, percentagem máxima, apenas comparável à dos Myliobatiformes (Antunes et al., 1999b: 118).

A ordem dos Carcharhiniformes constitui o grupo mais importante de tubarões dos mares actuais.

Compagno (1988) reconheceu 48 géneros e cerca de 194 espécies, repartidas em 8 famílias: Scyliorhinidae Gill, 1862, Proscylliidae Fowler, 1941, Pseudotriakidae, Gill 1893, Leptochariidae Gray, 1851, Triakidae Gray, 1851, Hemigaleidae Hasse, 1879, Carcharhinidae Jordan e Everman, 1896, e Sphyrnidae Gill, 1872. Ulteriormente outros autores propuseram alterações à sistemática de Compagno, com base no estudo da dentição dos Carcharhiniformes actuais.

A diversidade morfológica nos dentes dos Carcharhiniformes é marcante, dificultando, em muitos casos, a classificação.

Na Formação de Esbarrondadoiro estão representadas as famílias Scyliorhinidae, Triakidae, Hemigaleidae, Carcharhinidae e Sphyrnidae.

Os Scyliorhinidae, vulgarmente conhecidos por "cães do mar" habitam, na maior parte, a zona costeira dos oceanos. São uma família heterógenea; foram caracterizados os géneros Megascyliorhinus, Premontreia e Scyliorhinus.

De pequeno tamanho, os Triakidae estão representados por Triakis, Mustelus e Galeorhinus.

Da família Hemigaleidae foi identificado o género Paragaleus.

Os Carcharhinidae representam boa parte de todas as espécies de Carcharhiniformes. As espécies actuais desta família habitam mares quentes e temperados quentes, nas zonas costeiras e no mar alto. Nas jazidas estudadas estão presentes os géneros Galeocerdo, Rhizoprionodon e Carcharhinus.

Os Sphyrnidae são caracterizados pelas grandes expansões laterais cefálicas achatadas, pelo que se designam por “tubarões martelo". Sphyrna é o género descrito nesta bacia.

A jazida de Esbarrondadoiro assinala-se pela riqueza de táxones e de restos dentários. Vale de Zebro está em posição intermédia e por último Santa Margarida, onde todos os exemplares evidenciam forte abrasão.

A repartição diferente dos Carcharhiniformes nas três jazidas, assim como das outras ordens representadas e ainda as características sedimentares, apontam para áreas ecológicamente distintas.

O material está depositado no Departamento de Geociências da Universidade de Évora. 


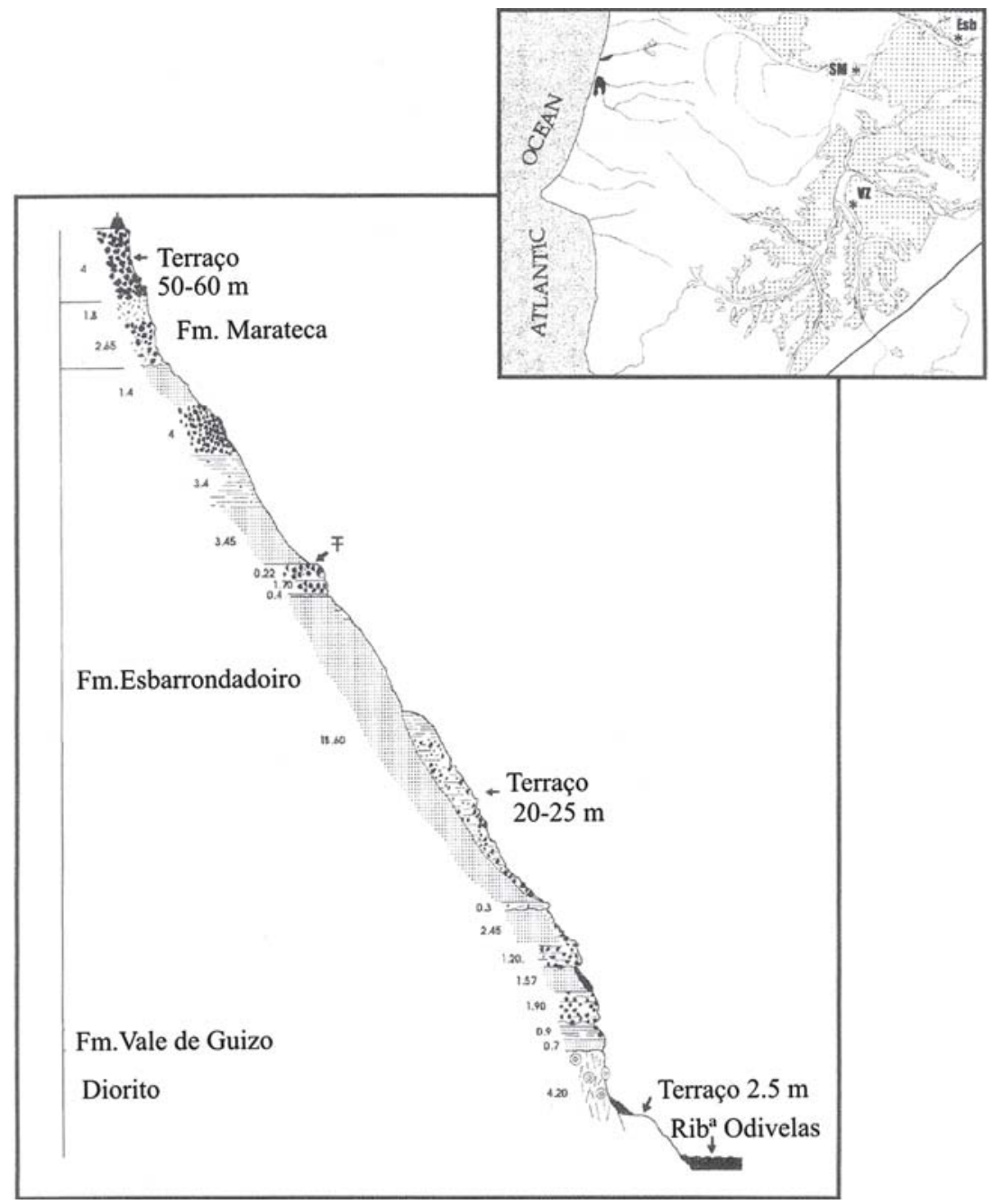

Figura 2. Bacia de Alvalade: a área ponteada corresponde aos depósitos messinianos. Sítios explorados: ESB - Esbarrondadoiro, SM - Santa Margarida do Sado, VZ, Vale de Zebro. Esbarrondadoiro: corte típico da Formação de Esbarrondadoiro: F nível de proveniência da fauna ictiológica e outra (Mamíferos, em especial). Espessura em metros.

Alvalade Basin: the pointed area corresponds to the distribution of the Messinian deposits. ESB - Esbarrondadoiro, SM - Santa Margarida do Sado, VZ, Vale de Zebro. Esbarrondadoiro: the Esbarrondadoiro typical section at Esbarrondadoiro. $F$ - level that yielded the ichthyologic and other (especially mammalian) fauna. Thickness in metres.

\section{SISTEMÁTICA}

ORDEM CARCHARHINIFORMES Compagno, 1973

Família Scyliorhinidae Gill, 1862

Sub-família Megascyliorhininae Cappetta, 1992

Género Megascyliorhinus Cappetta e Ward, 1977

Espécie-tipo: Megascyliorhinus cooperi Cappetta e Ward, 1977

\section{Megascyliorhinus miocaenicus}

\section{(Antunes e Jonet, 1970)}

Fig. 3a-g

Sinonímia (só a respeito de Portugal e da Bacia de Alvalade) 1970

Rhincodon miocaenicus nov. sp.; Antunes e Jonet, 152.
Megascyliorhinus miocaenicus (Antunes e Jonet, 1970); Cappetta e Ward.

Megascyliorhinus miocaenicus (Antunes e Jonet, 1970); Balbino, 65-66.

Material: 4 dentes.

Jazidas: Santa Margarida (1 dente) e Esbarrondadoiro (3 dentes).

Descrição: Dentes pequenos, robustos, unicúspides, de coroa afilada e inclinada para o interior da boca. Raíz espessa, com forte protuberância interna.

Um dente anterior tem coroa cónica, com estrias finas na base que se prolongam quase até a cúspide. A face labial é convexa, a lingual arredondada. Dois dentículos laterais, muito reduzidos, ladeiam a cúspide. A raíz, espessa, está parcialmente destruída.

Dois dentes laterais têm coroa afilada, inclinada para o interior da boca. A face labial é fortemente convexa. Tanto a face 
labial como a lingual possuem finas estrias que vão até a cúspide. Os dois dentículos laterais são robustos, aguçados, bem separados da coroa, com estriação. A raíz é robusta e alta; corresponde a cerca de metade da altura do dente. As faces lateral e interna são arredondadas e salientes; a basilar possui forte sulco que praticamente separa a raíz em 2 lobos. O foramen central abre-se no sulco.

Discussão: Antunes e Jonet (1970: 153 e est. 9 fig. 4244) atribuem a Rhincodon dentes semelhantes aos agora estudados; a atribuição genérica não se confirma, mas sim a espécie, que permanece válida. No entanto, já então Antunes e Jonet (1970: 154) haviam notado que "les caractères morphologiques de la racine de ces dents, semblent identiques à ceux de la dent décrite par Cappetta (1970) comme Rhincodon sp. mais il y a quelques différences en ce qui concerne la couronne". A criação de um género novo por Cappetta e Ward representa, afinal, uma maior valorização das diferenças.

No caso em estudo, a coroa afilada; a face labial muito convexa; a estriação muito acentuada; os dentículos aguçados e estriados; a robustez da raíz e a forte protuberância interna são características que justificam a atribuição dos dentes em estudo a Megascyliorhinus miocaenicus.

\section{Sub-família Premontreinae Cappetta, 1992} Género Premontreia Cappetta, 1992

Sub-género Oxyscyllium Noubhani e Cappetta, 1997

Espécie-tipo: Premontreia degremonti Cappetta, 1992.

\section{Premontreia (Oxyscyllium) cf. dachiardi (Lawley, 1876)}

Fig. 3h-m

Catulus (Scyllium) aff. minutissimus (Winkler); Zbyszewski e Almeida, 348-349.

1954 Catulus af. minutissimus (Winkler); Serralheiro, 66. 1970 Scylliorhinus distans (Probst); Antunes et Jonet, 58.

1995 Premontreia (Oxyscyllium) cf. dachiardi (Lawley, 1876); Balbino, 68-69.

1999b Premontreia (Oxyscyllium) cf. dachiardi; Antunes, Balbino e Cappetta, 116.

Material: 299 dentes.

Jazidas: Santa Margarida (48 dentes), Esbarrondadoiro (225) e Vale de Zebro (26).

Descrição: Dentes de tamanho pequeno a médio, com raíz massiva e sulco profundo.

Os dentes sinfisários são pequenos. A raíz, massiva, tem face basilar de contorno subcircular e sulco médio muito estreito. A coroa é muito curta, atarracada, inclinada para o interior da boca; as faces externa e interna são fortemente convexas. Existe um par de dentículos laterais na base da coroa.

Os dentes laterais anteriores, com face basilar plana e larga, possuem uma protuberância muito desenvolvida na face lin-

gual. O foramen abre-se no sulco médio da raíz. Nalguns dentes, há um ou dois foramina laterais internos de cada lado da protuberância. A coroa, desenvolvida e ponteaguda, pode apresentar perfil levemente sigmoidal. A coroa é ladeada por dois pares de dentículos laterais bastante desenvolvidos, ponteagudos e de forma triangular.

Nos dentes posteriores, a raíz é mais desenvolvida do que a coroa. Esta, baixa e larga, inclinada para a comissura, está ladeada por um a dois pares de fortes dentículos laterais.

Em muitos exemplares, há ornamentação acentuada na parte externa da coroa e nos dentículos laterais. As nervuras, verticais e paralelas, podem chegar até meio da coroa, mas estão normalmente limitadas à base. Embora predominem os exemplares ornamentados, as formas lisas também estão representadas.

Discussão: Os nossos exemplares têm grandes afinidades com os do Miocénico do Languedoc descritos por Cappetta (1970: 41-42, est. 9 figs. 1-18) como Scyliorhinus distans. Cappetta e Nolf (1991) caracterizam dentes semelhantes aos das nossas jazidas, classificando-os como S. dachiardi Lawley, 1876. É com base nos trabalhos de Cappetta (1992) e Noubhani (1993) que atribuímos os dentes aos citados género Premontreia e subgénero Oxyscyllium.

\section{Sub-família Scyliorhininae Gill, 1862 Género Scyliorhinus Blainville, 1816}

Espécie-tipo: Squalus canicula Linnaeus, 1758

\section{Scyliorhinus joleaudi Cappetta, 1970}

Fig. 4a-e

1979

1978

1995

$1999 b$
Scyliorhinus fossilis (Leriche); Antunes e Jonet, 159 Scyliorhinus fossilis (Leriche); Jonet, 59. Scyliorhinus joleaudi Cappetta, 1970; Balbino, 70. Scyliorhinus joleaudi; Antunes, Balbino et Cappetta, 116.

Material: 11 dentes.

Jazidas: Santa Margarida (1 dente), Esbarrondadoiro (10).

Descrição: Dentes pequenos, com raíz espessa.

Os dentes anteriores têm coroa direita (ligeiramente inclinada para a comissura em alguns exemplares), larga na base e afilada em direcção à cúspide. A raíz possui protuberância interna desenvolvida e face basilar larga. O limite raíz-coroa está bem marcado na face externa.

Os dentes laterais possuem um par de dentículos massivos nas expansões laterais da coroa, que apresenta nervuras finas na base. Nos dentes mais laterais, perto da comissura, a coroa é inclinada e as expansões laterais constituem verdadeiros talões. O talão mesial, mais desenvolvido que o distal, pode não ter dentículos. As nervuras continuam evidentes na base da coroa. A raíz modifica-se e os lobos afastam-se, determinando um maior ângulo de abertura. O lobo anterior é mais longo do que o posterior. Há dentes laterais sem dentículos. 

Discussão: Nesta espécie, os dentes são semelhantes aos de Scyliorhinus canicula Linnaeus, 1758 e S. stellaris Linnaeus, 1758, com as quais estabelecemos comparação. Semelhantes a $S$. canicula pelas dimensões dentárias, aproximam-se dos de $S$. stellaris pela morfologia. Leptocharias smithii Müller e Henle, 1839, espécie actual com dimorfismo sexual acentuado, também é comparável. No entanto: a existência de nervuras bem marcadas na base da coroa, subindo quase até a cúspide; o rebordo mais acentuado no limite coroa-raíz; as nervuras nos dentículos; a maior espessura da raíz, com dois lobos nitidamente separados, impedem esta atribuição específica. Por esta razão, e após comparação com dentes de $S$. joleaudi, espécie descrita por Cappetta (1970: 43, est. 10 fig. 1-7), cremos poder atribuir-lhe os nossos exemplares.

Família Triakidae Gray, 1851

Sub-família Triakinae Gray, 1851

Género Triakis Müller e Henle, 1838

Espécie-tipo: Triakis scyllium Müller e Henle, 1839

\section{Triakis cf. costamagnai Cappetta e Nolf, 1991} Fig. 4f-g

1995

Triakis cf. costamagnai Cappetta e Nolf, 1991; Balbino, 73-74.

1999b Triakis cf. costamagnai; Antunes, Balbino e Cappetta, 116.

Material: 3 dentes.

Jazidas: Santa Margarida (2 dentes) e Esbarrondadoiro (1 dente). Descrição: Os dentes anteriores, pequenos, são quase simétricos, com coroa direita, aguçada e larga na base. Um exemplar tem coroa triangular. Os dentículos laterais são baixos, massivos, pouco evidentes; o distal pode ser mais desenvolvido do que o mesial.

Na face externa, a coroa sobrepõe-se nitidamente à raíz, constituindo um rebordo. A face externa possui nervuras verticais, mais acentuadas nos talões do que na parte central. Em vista labial, o rebordo forma uma convexidade mediana quase paralela ao bordo basilar da raíz. A face lingual da coroa é completamente lisa.

A raíz é espessa, com lobos dissimétricos, arredondados nas extremidades; a protuberância interna está bem desenvolvida. O sulco é profundo e estreito. A face labial é menos elevada do que a face lingual; esta apresenta vários foramina que parecem alinhados de um e outro dos lados do sulco.

Discussão: Os nossos exemplares foram comparados com a dentição de várias espécies. Em Triakis acutipinna Kato, 1968; T. maculata Kner e Steindachner, 1866; e T. megalopterus Smith, 1849, os dentes são mais massivos, com cúspides espessas e sem bordos cortantes.

Outras espécies, T. scyllium Müller e Henle, 1839 e T. semifasciata Girard, 1854 têm características muito diferentes relativamente aos dentes de Alvalade. Em T. scyllium os dentes são mais espessos, sobretudo a nível da raíz. A base da coroa não tem nervuras na face externa; se, por excepção, aparecem nalguns dentes, são mais largas e prolongam-se até a cúspide. Em T. semifasciata os dentes são, de igual modo, mais espessos, sem nervuras e com bordo basal muito saliente.

Quando há nervuras, nos machos, estas são mais acentuadas e em menor número. Comparativamente com a espécie actual Iago omanensis Norman, 1939 encontramos diferenças na cúspide e na raíz, bem como nas nervuras da base da coroa. Em I. omanensis, a coroa é mais curta e larga na base; o rebordo labial é mais saliente e mais plissado; o perfil labial é mais côncavo; a raíz, menos espessa e de face basilar plana.

Pelas razões invocadas e pela observação dos dentes figurados por Cappetta et al. (1991, est. 3, figs. 1 e 2), julgamos poder afirmar que os nossos exemplares pertencem ao mesmo grupo morfológico de T. costamagnai.

Género Mustelus Link, 1790

Espécie-tipo: Squalus mustelus Linnaeus, 1758

Mustelus sp.

Fig. $4 \mathrm{~h}-\mathrm{j}$

1995 Mustelus sp.; Balbino, 75-76.

1999b Mustelus sp.; Antunes, Balbino e Cappetta, 116.

Material: 143 dentes.

Jazidas: Santa Margarida (23 dentes), Esbarrondadoiro (119) e Vale de Zebro (1).

Descrição: Os dentes são pequenos, com coroa deprimida, levemente cuspidada na parte central. Na face labial, a coroa sobre-

Figura 3. a-g. Megascyliorhinus miocaenicus (Antunes e Jonet, 1970), x 7.5. a, b, dente da região sinfisária (ESB 1a), a, labial; b, perfil. c, d, dente anterior (ESB 2a), c, labial; d, lingual. e-g, dente latero - anterior (ESB 3a), e, labial; f, lingual; g, basilar. h-m. Premontreia (Oxyscyllium) cf. dachiardi (Lawley, 1876), x 7.5. h, i, dente da região sinfisária (ESB 4a), h, labial; i, lingual. j, k, dente anterior (ESB 5a), j, lingual; k, perfil. l, m, dente lateral (ESB 6a), l, labial; m, lingual. $\boldsymbol{a}-\boldsymbol{g}$. Megascyliorhinus miocaenicus (Antunes e Jonet, 1970), x 7.5. a, b, symphysial tooth (ESB 1a), a, labial view; b, profile. $\boldsymbol{c}, \boldsymbol{d}$, anterior tooth (ESB $2 a), \boldsymbol{c}$, labial, and $\boldsymbol{d}$, lingual views. $\boldsymbol{e}-\boldsymbol{g}$, lateral-anterior tooth (ESB $3 a) \boldsymbol{e}$, labial; $\boldsymbol{f}$, lingual; and $\boldsymbol{g}$, basal views. $\boldsymbol{h}-\boldsymbol{m}$. Premontreia (Oxyscyllium) $c f$. dachiardi (Lawley, 1876), $x$ 7.5. $\boldsymbol{h}$, $\boldsymbol{i}$, symphysial tooth (ESB 4a), $\boldsymbol{h}$, labial; $\boldsymbol{i}$, lingual views. $\boldsymbol{j}, \boldsymbol{k}$, anterior tooth (ESB 5a), $\boldsymbol{j}$, lingual view; $\boldsymbol{k}$, profile. $\boldsymbol{l}, \boldsymbol{m}$, lateral tooth (ESB 6a), $\boldsymbol{l}$, labial; $\boldsymbol{m}$, lingual views. 

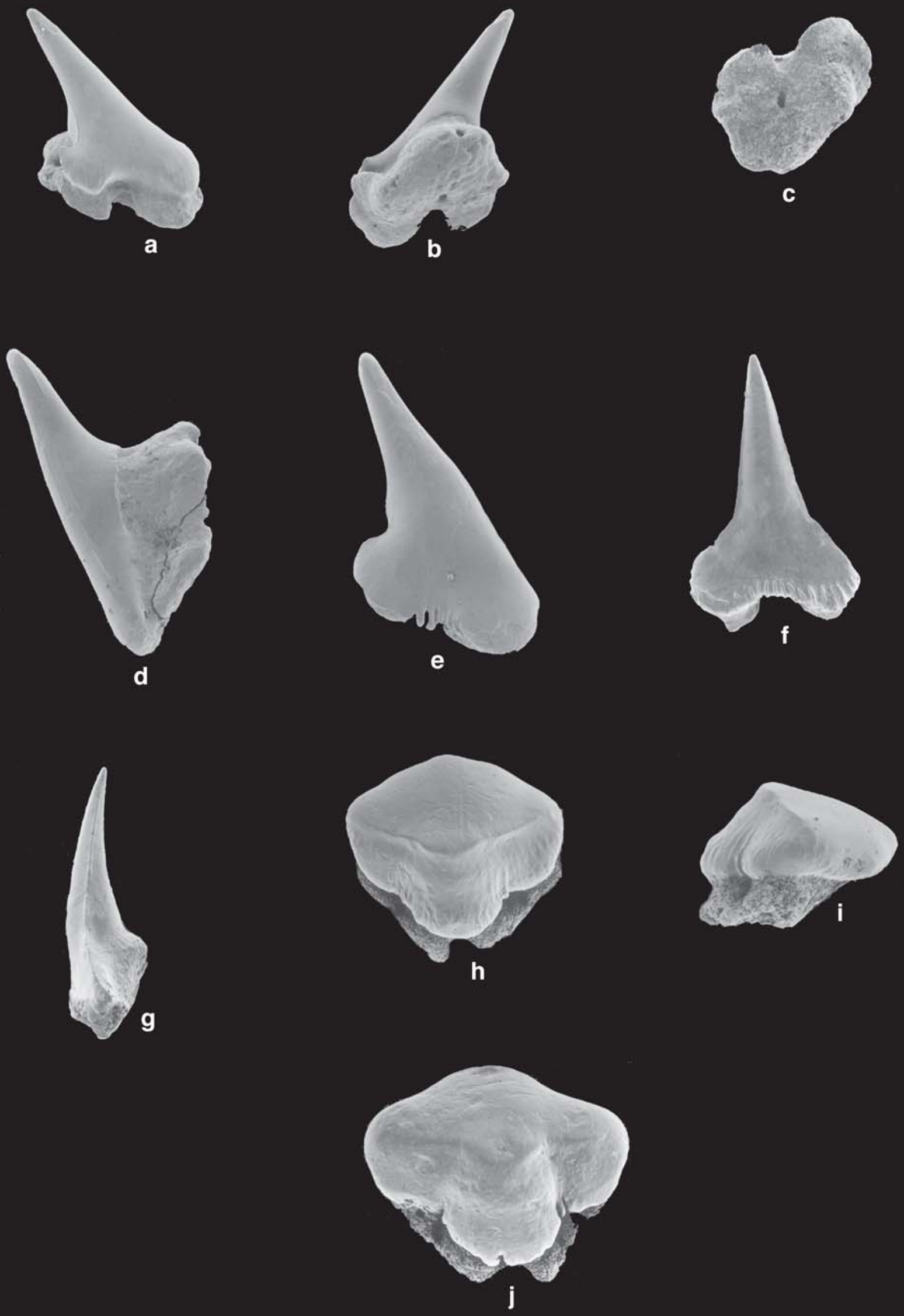
põe-se francamente à raíz; forma um painel mediano que, às vezes, ultrapassa o limite da raíz. Na face lingual, a raíz é mais alta que a coroa. Esta apresenta nervuras mais ou menos vincadas em ambas as faces. A raíz é massiva, com sulco mediano grande e profundo; apresenta vários foramina nas faces labial e lingual.

Os dentes anteriores são comprimidos mesio-distalmente. A coroa, massiva, é maior do que a raíz.

Nos dentes laterais, a coroa é estriada mesio-distalmente; na face labial abrem-se 4 foramina no limite coroa-raíz.

Alguns dentes, possivelmente de machos, apresentam coroa medianamente mais ponteaguda.

Discussão: Foram observados exemplares de espécies actuais - Mustelus mustelus Linnaeus, 1758, Mustelus asterias Cloquet, 1821, Mustelus californicus Gill, 1864, Mustelus mosis Ehrenberg e Emprich, 1889, Mustelus norrisi Springer, 1940, Mustelus canis Mitchill, 1815, Mustelus schmitti Springer, 1940, e Mustelus mediterraneus Quignard e Capape, 1972.

Os dentes fósseis aproximam-se de M. mustelus. As diferenças entre os dentes inferiores são pouco acentuadas, mas os superiores são bastante diferentes.

Em M. asterias os dentes são morfologicamente semelhantes aos dentes em estudo, mas há diferenças no tamanho e quanto ao limite coroa-raíz.

Os dentes de $M$. mediterraneus têm coroa muito mais ponteaguda do que os das jazidas de Alvalade.

É muito difícil relacionar os nossos exemplares com as espécies actuais observadas, uma vez que todas apresentam características muito semelhantes. Além disso, nos Mustelus é importante a heterodôncia sexual e ontogénica. Estas razões levam-nos a deixar em aberto a nomenclatura desta espécie.

Sub-família Galeorhininae Gill, 1862

Género Galeorhinus Blainville, 1816

Espécie-tipo: Galeorhinus galeus Blainville, 1816

\section{Galeorhinus gonçalvesi Antunes, Balbino e Cappetta, 1999a}

Fig. 5 a-c, e-g

1995 Galeorhinus gonçalvesi nov. sp.; Balbino, 78-80 (nomen nudum).

1999a Galeorhinus gonçalvesi nov. sp.; Antunes, Balbino e Cappetta, 104, figs. 1-7.

1999b Galeorhinus gonçalvesi; Antunes, BalbinoeCappetta, 116.
Material: 12 dentes.

Jazidas: Santa Margarida (2 dentes), Esbarrondadoiro (8) e Vale de Zebro (2).

Descrição: Os dentes possuem coroa larga na base e cúspide afilada, inclinada para a comissura. O talão mesial, longo, está unido ao bordo cortante da coroa. Este, ligeiramente convexo, tem perfil um pouco côncavo perto da cúspide. O bordo cortante distal, algo convexo, é quase rectilíneo em alguns exemplares. O talão comissural, bem separado da coroa, apresenta 4 dentículos de tamanho decrescente em direcção à raíz. Na face labial, a coroa apresenta rebordo saliente, rectilíneo, com uma pequena depressão central sobreposta à raíz. Na face externa, a raíz é curta, de perfil côncavo, com vários foramina. A face interna da raíz, bastante desenvolvida, tem grande protuberância central onde se abre um sulco largo e profundo. Vários foramina abrem-se em cada lobo da raíz.

Num dente de posição muito lateral a coroa é muito baixa, pouco maior que a raíz. O bordo cortante mesial é rectilíneo, inclinado para a comissura. O bordo distal, muito reduzido, é também rectilíneo. O talão distal, que não se diferencia da cúspide, é denticulado. Há dois dentículos quase indistintos, muito espessos. $\mathrm{Na}$ face labial, a coroa apresenta um rebordo rectilíneo que se sobrepõe à raíz. Esta possui dois lobos de tamanho diferente, o mesial muito maior que o distal, separados por um sulco profundo.

Discussão: Pela morfologia, denticulação e tipo de raíz, os dentes descritos distinguem-se imediatamente dos de algumas espécies de Carcharhinidae atribuídas outrora a Galeorhinus. Afastam-se, também, de G. galeus, cujos dentes têm coroa larga, bordo mesial um pouco côncavo, bordo distal com dois dentículos bem desenvolvidos e os outros (4 a 6 ) muito mais pequenos e quase indistintos. O rebordo tem perfil côncavo no limite coroa-raíz.

Os nossos exemplares distinguem-se da forma miocénica comum, Galeorhinus affinis Probst, 1878. Os dentes de G. affinis têm coroa mais larga, denticulação mais acentuada, bordo cortante mesial muito convexo e rebordo menos acentuado no limite coroa-raíz.

A distinção é evidente relativamente a espécies do Eocénico: G. minutissimus Arambourg, 1952 possui dentes mais pequenos, cúspide mais fina, raíz menos alta e menos profunda. Em G. cuvieri Agassiz, 1835 os dentes têm cúspide mais larga e bordo cortante mesial convexo.

Assim, e de acordo com as características referidas, são de atribuir os exemplares em estudo a G. gonçalvesi.

Figura 4. a-e. Scyliorhinus joleaudi Cappetta, 1970, x 20.5. a, b, dente da região sinfisária (ESB 7a), a, labial; b, lingual; c, basilar. d, e, dente anterior (ESB 8a), d, perfil; e, labial. f-g. Triakis cf. costamagnai Cappetta e Nolf, 1991, x 20, dente anterior (ESB 9a), f, labial; g, perfil. h-j. Mustelus sp., x 20.5. h-i, dente anterior (ESB 10a), h, labial; i, perfil. j, dente anterior (ESB 11a), labial.

a-e. Scyliorhinus joleaudi Cappetta, 1970, x 20.5. a, b, symphysial tooth (ESB 7a), a, labial; b, lingual; and c, basal views. $\boldsymbol{d}, \boldsymbol{e}$, anterior tooth (ESB 8a), d profile; $\boldsymbol{e}$, labial view. $\boldsymbol{f}$-g. Triakis $c f$. costamagnai Cappetta e Nolf, 1991, x 20, anterior tooth (ESB 9a), $\boldsymbol{f}$, labial view; $\boldsymbol{g}$, profile. $\boldsymbol{h}$-j. Mustelus sp., $x$ 20.5. h-i, anterior tooth (ESB 10a), $\boldsymbol{h}$, labial view; $\boldsymbol{i}$, profile. $\boldsymbol{j}$, anterior tooth (ESB 11a), labial view. 

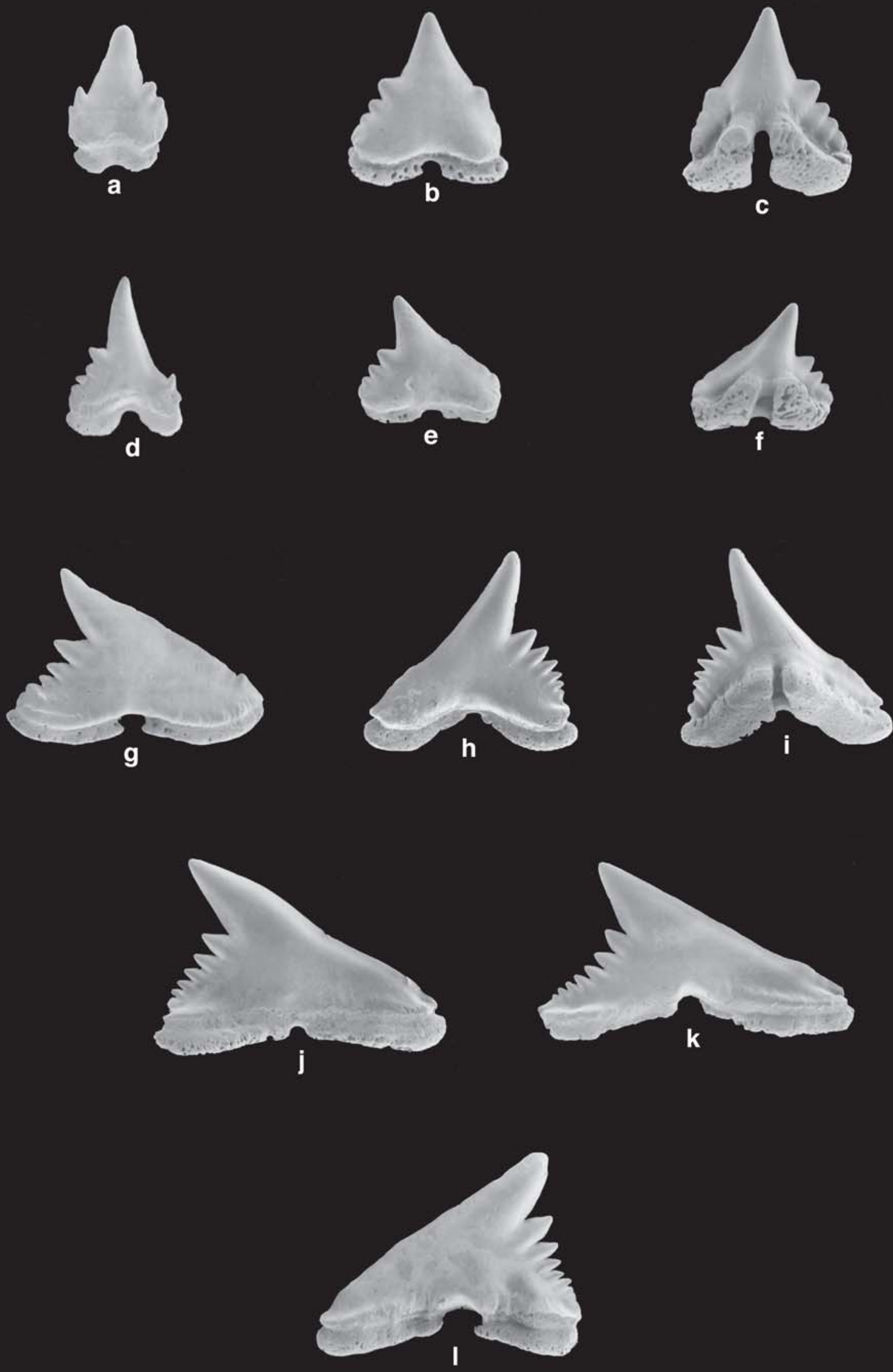
Família Hemigaleidae Hasse, 1879

Sub-família Hemigaleinae Hasse, 1879

Género Paragaleus Budker, 1935

Espécie-tipo: Paragaleus gruveli Budker, 1935

\section{Paragaleus antunesi Balbino e Cappetta, 2000 Figs. 5d,h-1 e 6a-d}

1995

Paragaleus antunesi nov. sp.; Balbino, 81-84 (nomen nudum).

1999b Paragaleus antunesi; Antunes, Balbino e Cappetta, 116 (nomen nudum).

2000 Paragaleus antunesi; nov. sp.; Balbino e Cappetta, 35, est. 1 figs. $1-10$, est. 2 figs. 1-12.

Material: 420 dentes.

Jazidas: Santa Margarida (96 dentes), Esbarrondadoiro (296) e Vale de Zebro (28).

Descrição: Os dentes desta espécie, muito bem representada, permitem reconstituir a dentição.

Dentes superiores: coroa triangular, larga na base e inclinada para a comissura. Bordo cortante mesial fortemente convexo, bordo distal côncavo. O talão distal apresenta 5 a 7 dentículos triangulares, de tamanho decrescente em direcção à raíz. A face labial é convexa. Limite coroa-raíz rectilíneo. O limite coroa-raíz é rectilíneo, apresentando, alguns exemplares, uma chanfradura central.

A raíz, bem desenvolvida, possui uma protuberância interna acentuada; na parte central abre-se um sulco profundo que separa a raíz em dois lobos, nem sempre do mesmo tamanho.

Nos dentes mais laterais, a coroa é larga e fortemente inclinada para a comissura. O bordo cortante mesial não se distingue do talão. O bordo cortante distal, muito curto, situa-se ao mesmo nível dos dentículos e quase não se distingue destes. A raíz tem face basilar plana, com foramen central. Os dentes laterais são menos altos que os anteriores (os primeiros têm entre 5 e $6 \mathrm{~mm}$ de altura e os anteriores 3 a $4 \mathrm{~mm}$ ).

Os dentes sinfisários são pequenos. A coroa tem secção arredondada, fortemente inclinada para o interior da boca. $\mathrm{O}$ talão mesial possui dois dentículos; o distal pode, ou não, ser denticulado.

Dentes inferiores: a coroa é estreita e afilada, inclinando um pouco para o interior da boca. O bordo cortante distal é quase rectilíneo e a base apresenta 4 dentículos. O limite coroa-raíz forma um rebordo pouco acentuado, rectilíneo. As características da raíz são quase as mesmas dos dentes superiores. Contudo, o lobo mesial é maior do que o lobo distal.

Nos dentes anteriores, a coroa é triangular, direita, boleada nas faces externa e interna. Há dois verdadeiros talões que, não sendo denticulados, podem elevar-se na extremidade para formar uma espécie de dentículo. A raíz tem protuberância interna forte. Na parte central abre-se um sulco profundo, oblíquo, a dividir a raíz em dois lobos. Nalguns dentes, vêem-se foramina de um e outro lado do sulco.

Discussão: Os dentes disponíveis foram comparados com dentes isolados de Chaenogaleus. Há semelhanças entre os dentes superiores, mas os inferiores são muito diferentes. Em Chaenogaleus, o bordo cortante da coroa estende-se sobre a raíz e o limite é arredondado. Nos extremos, podem apresentar duas pequenas saliências redondas que lembram dentículos. Nenhuma destas características se verifica nos nossos exemplares. Os dentes superiores, embora morfologicamente semelhantes, mostram uma pequena diferença: a cúspide dos dentes de Chaenogaleus ultrapassa sempre o limite da raíz, enquanto em Paragaleus a cúspide ou se situa ao nível da raíz ou aquém do extremo da raíz.

Comparados com Paragaleus pulchellus Jonet, 1966, há diferenças na coroa (muito mais esguia em $P$. pulchellus), na denticulação (menos dentículos nitidamente separados do bordo distal da coroa) e na raíz (sulco central oblíquo, lobos distal e mesial de tamanho diferente).

A espécie fóssil separa-se igualmente da actual $P$. pectoralis Garman, 1906. Os dentes superiores têm coroa mais larga, dentículos mais grossos, bordo distal convexo. Alguns dentes possuem um pequeno dentículo no bordo cortante mesial, bem como uma pequena depressão no limite coroa-raíz.

É de P. antunesi Balbino e Cappetta, 2000 que os exemplares mais se assemelham a nível da coroa e da raíz, o que justifica a classificação proposta.

Família Carcharhinidae Jordan e Everman, 1896 Sub-família Galeocerdinae Whitley, 1934 Género Galeocerdo Müller e Henle, 1837

Espécie-tipo: Squalus cuvier Peron e Lesueur, 1822

Figura 5. a-c, e-g. Galeorhinus gonçalvesi Antunes, Balbino e Cappetta, 1999a. a, Dente da região sinfisária (ESB 12a), labial, x 9.25. b, c, dente da região sinfisária (ESB 13a), b, labial, x 9.25; c, lingual, x 9.75. e, f, dente anterior (ESB 15a), e, labial; f, lingual, x 9.25. g, dente lateral (ESB 16a), labial, x 9.25. d, h-l. Paragaleus antunesi Balbino e Cappetta, 2000, d, dente parasinfisário (ESB 14a), labial, x 7.5. h-i, dente da região sinfisária (VZ 1a), h, labial; i, lingual x 8. j, dente lateral (ESB 17a), labial. k, dente lateral (ESB 18a), labial. l, dente lateral (ESB 19a), labial.

$\boldsymbol{a}-\boldsymbol{c}, \boldsymbol{e}-\boldsymbol{g}$. Galeorhinus gonçalvesi Antunes, Balbino e Cappetta, 1999a. a, symphysial tooth (ESB 12a), labial view, x 9.25. b, $\boldsymbol{c}$, symphysial tooth (ESB 13a), b, labial, x 9.25; and c, lingual views, $x$ 9.75. e, f, parasymphysial tooth (ESB 15a), $\boldsymbol{e}$, labial; $\boldsymbol{f}$, lingual views $x$ 9.25. g, lateral tooth (ESB 16a), labial view x 9.25.d, h-l. Paragaleus antunesi Balbino e Cappetta, 2000, $\boldsymbol{d}$, parasymphysial tooth (ESB 14a), labial view, $x$ 7.5. h-i, symphysial tooth (VZ 1a), $\boldsymbol{h}$, labial; $\boldsymbol{i}$, lingual views $x$ 8. $\boldsymbol{j}$, lateral tooth (ESB 17a), labial view. , lateral tooth (ESB 18a), labial view. l, lateral tooth (ESB 19a), labial view. 



\section{Galeocerdo aduncus Agassiz, 1843}

Fig. 6e

1887 Galeocerdo aduncus (Agassiz); Bonança, 481.

1904 Galeocerdo; Dollfus, Cotter e Gomes, 7.

1950 Galeocerdo aduncus (Agassiz); Zbyszewski e Almeida, 343.

1954 Galeocerdo aduncus (Agassiz); Serralheiro, 59-60.

1966 Galeocerdo aduncus (Agassiz); Jonet, 67.

1970 Galeocerdo aduncus (Agassiz); Antunes e Jonet, 165.

1975 Galeocerdo aduncus (Agassiz); Jonet, 204.

1978 Galeocerdo aduncus (Agassiz); Jonet, 29.

1995 Galeocerdo aduncus (Agassiz); Balbino, 86-88.

1999b Galeocerdo aduncus; Antunes, Balbino e Cappetta, 116.

Material: 1 dente.

Jazida: Esbarrondadoiro.

Descrição: Dente lateral, com a coroa inclinada para a comissura. O bordo cortante mesial, fortemente convexo e serrilhado em toda a extensão, é dificilmente separável do talão mesial. O bordo cortante distal é serrilhado; existe um forte "entalhe" a separá-lo do talão respectivo. Este tem 7 dentículos de tamanho decrescente a partir da cúspide. Os dentículos, nitidamente distintos uns dos outros, são serrilhados e de forma convexa. Há, pois, uma serrilhação complexa, com serrilha primária composta por dentículos por sua vez serrilhados, o que constitui um carácter progressivo, bem visível na espécie actual Galeocerdo cuvier - v. Antunes (1978).

A raíz é desenvolvida, com protuberância interna pouco acentuada.

O limite coroa-raíz é marcado, na face interna, por um sulco mais desenvolvido na parte mesial. A coroa sobrepõe-se à raíz na face labial. A face lingual é nitidamente convexa, enquanto a labial é côncava.

Discussão: O nosso exemplar foi comparado com dentes de Galeocerdo aduncus descritos e figurados por Antunes e Jonet (1970: 165-167, est. XI, figs. 59-62) e por Cappetta (1970: 50-52, est. 12, figs. 1-21).

É de realçar o estádio muito evoluído do Galeocerdo, já próximo de G. cuvier, que ocorre no Pliocénico (Antunes, 1978).

Os dentes de G. aduncus do Miocénico de Maryland figurados por Leriche (1942) parecem ter coroa mais direita e mais aguda do que o de Esbarrondadoiro. Génault (1993: 33, figs. 52-57) figura dentes que conferem com
G. aduncus; no entanto, são maiores e têm bordo anterior da coroa mais convexo; este facto está talvez relacionado com a posição nas maxilas, ou com variabilidade.

Sub-família Carcharhininae Jordan e Everman, 1896

Tribo Rhizoprionodontini Compagno, 1988

Género Rhizoprionodon Whitley, 1929

Espécie-tipo: Carcharias (Scoliodon) crenidens Klunzinger, 1879

\section{Rhizoprionodon sp.}

Fig. 6f-g

1995 Rhizoprionodon sp.; Balbino, 89-91.

2000 Rhizoprionodon sp.; Antunes, Balbino e Cappetta, 116.

Material: 18 dentes.

Jazidas: Santa Margarida (4 dentes) e Esbarrondadoiro (14). Descrição: Os dentes são pequenos quando comparados com os das espécies actuais. É difícil separar os superiores dos inferiores; nestes, há acentuado dimorfismo sexual.

Os dentes laterais são alongados. A coroa é triangular, pouco elevada, larga na base, com tendência a aprumar-se na cúspide. Os bordos cortantes são perfeitamente lisos. O bordo mesial, em continuidade com o talão, é rectilíneo ou levemente côncavo na parte mesial da coroa. O bordo distal, mais curto, é quase rectilíneo; um "entalhe" bem marcado separa-o do talão comissural. Este talão pode ser liso ou denticulado. Os dentículos são grossos e baixos, às vezes serrilhados. A face externa da coroa é convexa na base, quase plana junto da cúspide. A face interna, também lisa, é sub-vertical e de perfil algo côncavo. O limite coroa-raíz é rectilíneo.

A raíz possui dois lobos separados por um sulco oblíquo; o lobo mesial é maior do que o distal.

Nos dentes muito laterais, a coroa é muito baixa e larga na base; o bordo mesial é longo e o distal muito curto. O talão distal possui um dentículo largo e baixo. Na face interna, a separação coroa-raíz é evidenciada por uma pequena depressão. A raíz é alongada e curta; o lobo mesial é mais longo que o distal.

Discussão: Os dentes das espécies actuais de Rhizoprionodon apresentam semelhanças com os de algumas espécies de Sphyrnidae e, ainda, com os do género monotípico Loxodon (L. macrorhinus Müller e Henle, 1838). Os den-

Figura 6. a-d. Paragaleus antunesi Balbino e Cappetta, 2000, x 18.5. Dentes inferiores. a, b, dente da região sinfisária (ESB 20a), a, labial; b, perfil. c, d, dente anterior (ESB 21a), c, labial; d, lingual. e. Galeocerdo aduncus Agassiz, 1843, x 4, dente lateral (ESB 22a), labial. f, g, Rhizoprionodon sp. f, dente lateral (ESB 23a), lingual. g, dente lateral (ESB $24 \mathrm{a}$ ), labial. h-i. Carcharhinus cf. leucas Valenciennes, 1839, x 3. h, i, dente superior lateral (ESB 25a), h, labial; i, lingual. $\boldsymbol{a}$-d. Paragaleus antunesi Balbino e Cappetta, 2000, x 18.5. Lower teeth. a, b, symphysial tooth (ESB 20a), a, labial; b, profile. $\boldsymbol{c}, \boldsymbol{d}$, anterior tooth (ESB 21a), $\boldsymbol{c}$, labial; $\boldsymbol{d}$, lingual views. $\boldsymbol{e}$. Galeocerdo aduncus Agassiz, 1843, x 4, lateral tooth (ESB 22a), labial view. $f, g$, Rhizoprionodon sp. $f$, lateral tooth (ESB 23a), lingual view. g, lateral tooth (ESB 24a), labial view. $\boldsymbol{h}-\boldsymbol{i}$. Carcharhinus $c f$. leucas Valenciennes, 1839, x 3. $\boldsymbol{h}$, i, lateral upper tooth (ESB 25a), $\boldsymbol{h}$, labial; and $\boldsymbol{i}$, lingual views. 
tes de L. macrorhinus distinguem-se pela cúspide inclinada para a comissura, de tal modo que a ponta ultrapassa em largura o bordo distal do dente. Além disso, na face labial do dente o limite coroa-raíz faz-se por um rebordo pouco saliente. Estas características estão ausentes em Rhizoprionodon.

Os dentes de Rhizoprionodon distinguem-se dos de Sphyrnidae pela raíz, mais alongada lateralmente. Os anteriores e laterais anteriores da mandíbula dos Sphyrnidae têm cúspide quase direita, levemente inclinada para o interior da boca. Os bordos cortantes da coroa, ligeiramente serrilhados em Sphyrna mokarran Ruppel, 1835 e em S. lewini Griffith e Smith, 1834 são sempre inteiros em Rhizoprionodon.

Segundo Cappetta (1987), o género Rhizoprionodon é conhecido no estado fóssil pelas espécies: Rhizoprionodon ganntourensis Arambourg, 1952, do Eocénico de Marrocos e da Bacia de Paris (= Scoliodon aff. ganntourensis Arambourg, 1952, descrito por Cappetta e Nolf (1981) do Auversiano de Ronquerolles); e Rhizoprionodon fischeuri Joleaud, 1912, do Miocénico de França e de Portugal. Os nossos exemplares diferem de $R$. ganntourensis pelos dentículos distais nitidamente menos desenvolvidos, de perfil baixo e levemente serrilhados. Os lobos da raíz estão no prolongamento um do outro; o sulco médio é menos acentuado. Em relação a $R$. fischeuri, os dentes estudados diferem pela coroa triangular mais larga na base e menos arredondada, bordo cortante mesial maior, raíz mais alongada e sulco mediano menos acentuado.

Os dentes fósseis foram ainda comparados com os de $R$. porosus Poey, 1861; $R$. lalandi Valenciennes, 1839; $R$. oligolinx Springer, 1964; e R. acutus Rüppel, 1837. Contudo, há diferenças muito acentuadas quanto ao tamanho dos dentes e à morfologia da coroa e da raíz.

Pelas razões invocadas e por considerarmos prematura a segregação de uma espécie nova com base no material estudado, optamos por deixar em aberto a determinação ao nível da espécie.

Sub-família Carcharhininae Jordan e Everman, 1896

Tribo Carcharhinini Jordan e Everman, 1896

Género Carcharhinus Blainville, 1816

Espécie-tipo: Carcharias melanopterus Quoy e Gaimard, 1824

\section{Carcharhinus cf. leucas Valenciennes, 1839}

Figs. 6h-i e 7a-b

1995 Carcharhinus cf. leucas Valenciennes, 1839; Balbino, 92-93.

1995 Carcharhinus cf. obscurus Lesueur, 1818; Balbino, 93-94.

1999b Carcharhinus cf. leucas; Antunes, Balbino e Cappetta, 116.

1999b Carcharhinus cf. obscurus; Antunes, Balbino e Cappetta, 116.

Material: 14 dentes.

Jazidas: Esbarrondadoiro (10 dentes), Vale de Zebro (4).

Descrição: Os dentes superiores, relativamente grandes, têm coroa larga, triangular. O bordo mesial é quase rectilíneo e o distal um pouco côncavo na base. Os bordos cortantes são fortemente serrilhados, assim como os talões. A face labial da coroa é plana, e a lingual convexa. No limite externo coroa-raíz existe uma ligeira concavidade com um sulco pouco acentuado. A raíz é alta na face labial; na face lingual está bem desenvolvida. A face basilar apresenta uma grande concavidade na parte central com perfil em V, determinando dois lobos ligeiramente afastados. Apresenta um sulco central onde se abre um grosso foramen a meio de uma nítida chanfradura. Alguns exemplares têm apenas um foramen pequeno na parte mediana da raíz. A face basilar é medianamente côncava; os extremos dos lobos são quase verticais.

Os dentes inferiores têm coroa direita, bem distinta dos talões. Entre os exemplares observados, é de notar o da fig. 7, b, que parece corresponder bem a um dos anteriores ( $1^{\mathrm{a}}$ ou 2 filas) de Carcharhinus leucas. Os bordos cortantes mesial e distal, bem como os talões são serrilhados. A raíz, espessa, apresenta um foramen circular na face lingual.

Discussão: Os nossos exemplares foram comparados com os de espécies actuais que, de igual modo, têm dentição robusta, com dentes superiores largos e triangulares: Carcharhinus obscurus Lesueur, 1818; Carcharhinus plumbeus Nardo, 1827; Carcharhinus leucas Valenciennes, 1839; Carcharhinus altimus Springer, 1950. Em C. altimus, os dentes são relativamente mais altos e afilados; os de $C$. plumbeus são muito mais aplanados labio-lingualmente; os de $C$. obscurus são mais largos, com raíz mais espessa e face labial menos alta; além disso, os bordos basais da raíz são quase sempre (à excepção dos das primeiras três filas) direitos, praticamente sem chanfradura. É de C. leucas que a forma representada na Bacia de Alvalade mais se aproxima.

Figura 7. a-b. Carcharhinus cf. leucas Valenciennes, 1839, x 3. a, dente superior anterior (ESB 25a), labial. b, dente inferior anterior (ESB 26a), labial. c. Carcharhinus cf. plumbeus Nardo, 1827, x 4, dente superior anterior (ESB 27a), labial. d. Carcharhinus cf. perezi Poey, 1876, x 4, dente inferior juvenil (ESB 28a), labial. e. Sphyrna sp. 1, x 7, dente lateral (ESB 29a), lingual. f. Sphyrna sp. 2, x 7, dente lateral (ESB 30a), labial.

$\boldsymbol{a}$-b. Carcharhinus $c f$. leucas Valenciennes, 1839, x 3. a, anterior upper tooth (ESB 25a), labial view. b, anterior lower tooth (ESB 26a), labial view. c. Carcharhinus $c f$. plumbeus Nardo, 1827, x 4, anterior upper tooth (ESB 27a), labial view. $\boldsymbol{d}$. Carcharhinus $c f$. perezi Poey, 1876, x 4, juvenile lower tooth (ESB 28a), labial view. e. Sphyrna sp. 1, x 7, lateral tooth (ESB 29a), lingual view. $f$. Sphyrna sp. 2, $x$ 7, lateral tooth (ESB 30a), labial view. 

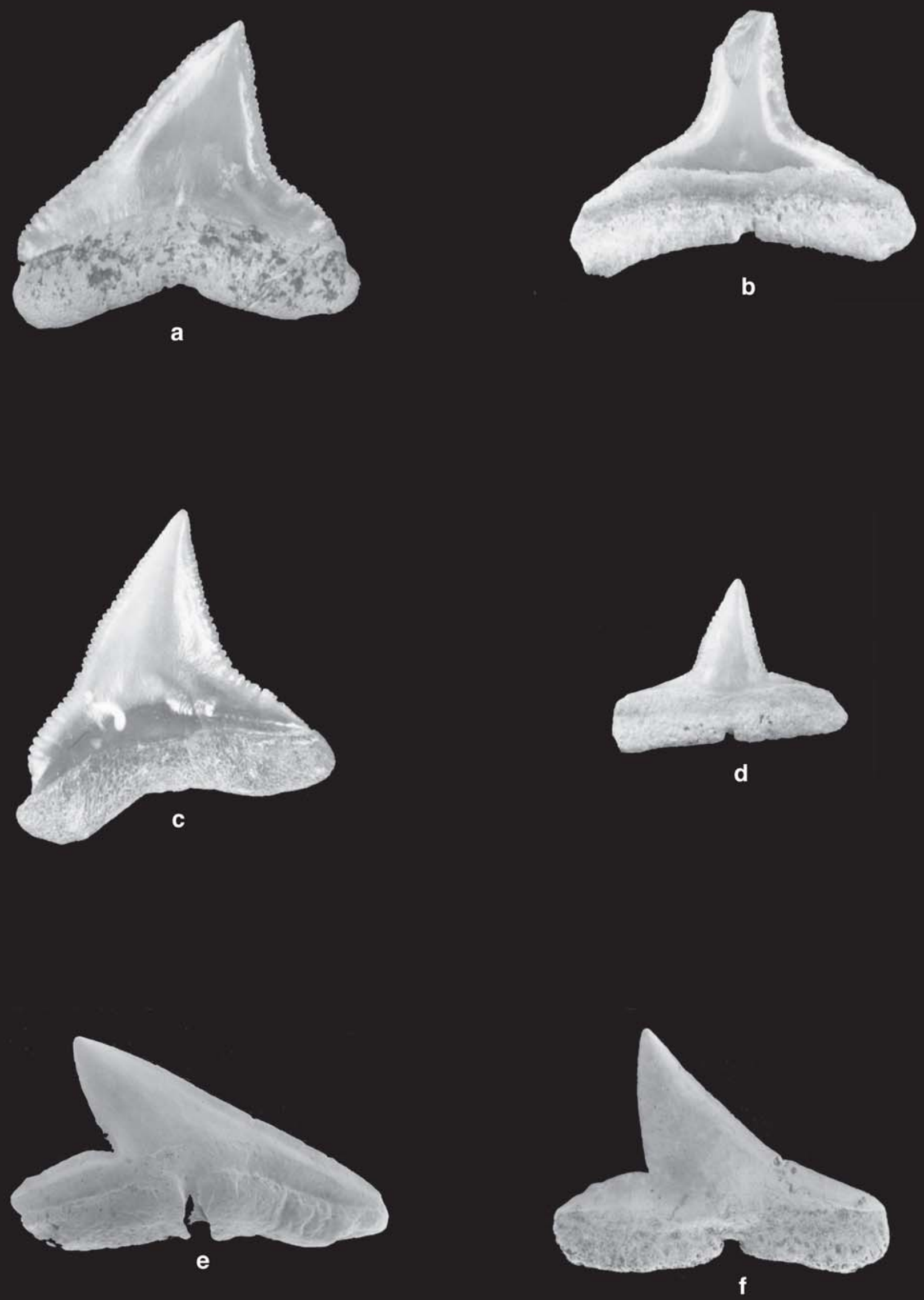
A maior parte dos dentes com aquelas características tem sido atribuída à espécie fóssil C. egertoni Agassiz, 1843. Porém, os nossos exemplares afastam-se de $C$. egertoni porque a cúspide é mais afilada e quase direita. Por outro lado, os dentes anteriores de C. leucas têm coroa menos larga, e o limite esmalte-raíz é ligeiramente côncavo na parte central enquanto que é rectilíneo em C. egertoni.

\section{Carcharhinus cf. plumbeus Nardo, 1827}

Fig. 7c

1995

Carcharhinus cf. plumbeus Nardo, 1827; Balbino, 9596.

1999b Carcharhinus cf. plumbeus; Antunes, Balbino e Cappetta, 116.

Material: 16 dentes.

Jazidas: Esbarrondadoiro (7 dentes) e Vale de Zebro (9). Descrição: Os dois dentes sinfisários têm coroa triangular muito curta e inclinada para o interior da boca. Os bordos cortantes são serrilhados. Os talões mesial e distal, também serrilhados, são muito curtos. Na face labial, a coroa sobrepõe-se à raíz, formando um rebordo saliente. A raíz é alta na face labial em toda a extensão; apresenta pequenos foramina circulares, dispersos. Mais desenvolvida na face lingual, apresenta um sulco profundo desde a base do esmalte até a base da raíz. Na face basilar, abre-se um foramen circular no interior do sulco.

Os dentes superiores têm coroa triangular ligeiramente aplanada labio-lingualmente, um pouco inclinada para a comissura. $\mathrm{O}$ bordo distal, bem separado do talão, é quase vertical. O bordo mesial é ligeiramente convexo a partir da separação do talão. Os bordos cortantes da coroa e os talões possuem serrilhado fino, regular. A raíz é relativamente pequena; a face basilar tem perfil cõncavo na parte central. Na face lingual, a raíz, espessa, é muito desenvolvida na zona mediana, onde se abre um foramen. Os extremos dos lobos da raíz são arredondados. Os dentes inferiores têm coroa triangular direita, com perfil algo sigmoidal; os bordos cortantes e os talões são serrilhados. A raíz é alta e menos alongada do que nos dentes superiores.

Alguns dentes de menor tamanho devem pertencer a indivíduos juvenis.

Discussão: A morfologia dos dentes apresenta semelhanças com a dos dentes superiores de coroa larga e triangular, como em algumas espécies actuais de Carcharhinus. Porém, a coroa aplanada labio-lingualmente, relativamente mais pequena, e a raíz menos espessa permitem distinguilos e reconhecer que conferem com os dentes de C. plumbeus $(=C$. milberti $)$.

\section{Carcharhinus cf. perezi Poey, 1876} Fig. 7d

1995 Carcharhinus cf. perezi Poey, 1876; Balbino, 96-98. 1999b Carcharhinus cf. perezi; Antunes, Balbino e Cappetta, 116.
Material: 565 dentes.

Jazidas: Santa Margarida (25 dentes), Esbarrondadoiro (380) e Vale de Zebro (160).

Descrição: Dentes superiores - os parasinfisários são de tamanho muito reduzido e de aspecto deformado. A coroa é baixa, triangular e inclinada para o interior da boca; os bordos cortantes e os talões (muito curtos) são serrilhados. A raíz, massiva e muito desenvolvida, é mais alta do que a coroa. Na parte central há um sulco muito profundo.

Os dentes anteriores têm coroa alta, direita e triangular. A face labial é um pouco convexa, com perfil algo sigmoidal. A face labial é abaulada medianamente. Os talões, oblíquos e serrilhados, estão bem separados da coroa. Os bordos distal e mesial da coroa são também serrilhados. Na face interna, a raíz, massiva, apresenta sulco mediano profundo; a face basilar tem perfil um pouco côncavo na parte central.

Nos dentes laterais, a coroa é ligeiramente inclinada para a comissura; os lobos da raíz estendem-se lateralmente. O bordo mesial, dentado e de perfil levemente convexo, está nitidamente separado do talão por uma espécie de sulco. Tem aqui início o denteado do talão, mais acentuado do que o da coroa. O bordo distal, rectilíneo, está bem separado do talão. Ambos são serrilhados, mas é no talão que as serrilhas são mais profundas. A face labial é medianamente convexa, com uma pequena depressão na base da coroa. O limite coroa-raíz é rectilíneo, com rebordo pouco saliente; na parte central, sobre o sulco da raíz, existe um pequeno "tablier". Na face lingual, a coroa é abaulada na base. A raíz é curta na face externa e mais desenvolvida na face interna, onde se abre um sulco mais ou menos profundo. O perfil da face basilar é ligeiramente côncavo.

Nos dentes de posição mais lateral, os talões (sobretudo o distal) apresentam serrilhado mais profundo.

Os dentes inferiores têm coroa triangular, direita e alta, com cúspide bem diferenciada do talão, com bordo mesial algo convexo e coroa estreitando na base; os bordos cortantes são finamente serrilhados, tal como os talões, que são curtos e pequenos. $\mathrm{O}$ esmalte da coroa sobrepõe-se ligeiramente à raíz na parte central. Os lobos da raíz, de bordos arredondados, estendem-se lateralmente. A raíz é um pouco mais espessa na face interna; está separada em dois lobos por um sulco vertical profundo.

Os dentes dos jovens são muito mais pequenos. Apresentam, no geral, a mesma morfologia.

Discussão: Os dentes fósseis foram comparados aos da espécie miocénica $C$. priscus Agassiz, 1843, com os quais apresentam algumas semelhanças. Porém, diferenças no tamanho dos dentes e na morfologia da coroa (os de C. priscus têm coroa mais estreita e separação coroa-talão menos nítida) afastam esta atribuição.

Relativamente às espécies actuais observadas, há semelhanças com $C$. plumbeus, que apresenta o mesmo dimorfismo entre a dentição superior e a inferior. Todavia, é com $C$. perezi que as afinidades são mais estreitas: coroa triangular, inclinada para a comissura nos dentes de posição mais lateral; talão distal nitidamente separado da coroa; bordo cortante distal quase rectilíneo e o mesial levemente convexo; raíz com chanfradura central a separar dois lobos, que podem apresentar ta- 
manhos diferentes. Pelas características referidas julgamos poder atribuir os dentes da Bacia de Alvalade a $C$. perezi.

Família Sphyrnidae Gill, 1872

Género Sphyrna Rafinesque, 1810

Espécie-tipo: Squalus zygaena Linnaeus, 1758

\section{Sphyrna sp. 1}

Fig. $7 \mathrm{e}$

1995 Sphyrna sp. 1; Balbino, 103-104.

1999b Sphyrna sp. 1; Antunes, Balbino e Cappetta, 116.

Material: 21 dentes.

Jazidas: Santa Margarida (3 dentes), Esbarrondadoiro (14) e Vale de Zebro (4).

Descrição: Dentes com coroa triangular larga, inclinada para a comissura. O bordo cortante mesial é, normalmente, convexo (nalguns exemplares pode ser mais direito); o bordo distal, rectilíneo, é quase perpendicular ao respectivo talão, do qual está nitidamente separado. Ambos os bordos são lisos, mesmo em grande ampliação. A face labial da coroa, plana, está separada da raíz pelo esmalte. A raíz é espessa, com os lobos no prolongamento um do outro. Na face interna, a coroa é arredondada. A raíz possui forte protuberância, fendida por um sulco central. Nos dentes laterais, a coroa inclina-se bastante para a comissura; a raíz alarga-se transversalmente. O bordo mesial é grande e convexo; o distal apresenta um dentículo subvertical.

Os dentes de posição muito lateral têm a coroa reduzida em relação à raíz.

Discussão: Estes dentes distinguem-se dos de Sphyrna arambourgi Cappetta, 1970 pela coroa mais massiva e menos elevada. Diferenciam-se dos dentes das espécies actuais Sphyrna lewini Griffith e Smith, 1834 e Sphyrna mokarran Rüppel, 1837 pela morfologia da coroa. Separam-se dos de Sphyrna tudes Valenciennes, 1822 pela coroa mais espessa e pelas características dos bordos cortantes distal e mesial. É de Sphyrna zygaena Linnaeus, 1758, descrita e figurada por Antunes e Jonet (1970: 197, est. 18, figs. 133-134; est. 19, figs. 133, 135-140; est. 20, fig. 141) e Antunes (1978: 72, est. 3, figs. 89-94), que mais se aproximam os nossos exemplares, mas os bordos da coroa serrilhados excluem a hipótese de pertencerem àquela espécie.

\section{Sphyrna sp. 2}

Fig. $7 f$

1995

Sphyrna sp. 2; Balbino, 105.

1999b Sphyrna sp. 2; Antunes, Balbino e Cappetta, 116.

Material: 39 dentes.

Jazidas: Santa Margarida (9 dentes), Esbarrondadoiro (21) e Vale de Zebro (9).
Descrição: Dentes anteriores com coroa triangular, larga na base, levemente inclinada para a comissura. O bordo cortante mesial apresenta perfil côncavo a rectilíneo. Em certos exemplares o talão mesial não se distingue da coroa. $\mathrm{O}$ tamanho do talão distal é variável; pode ser denticulado, com dentículos espessos. O perfil da face labial da coroa é ligeiramente sigmoidal. A raíz tem protuberância interna, com chanfradura central desenvolvida.

Nos dentes inferiores, a coroa é mais estreita e menos inclinada para a comissura. A raíz é massiva, com sulco central oblíquo. O lobo mesial da raíz é maior do que o distal.

Discussão: Esta espécie distingue-se de S. zygaena pelos dentes mais pequenos, com coroa estreita e bordos cortantes não denticulados. Distingue-se também de $S$. tudes pela morfologia da coroa. Assemelha-se a Sphyrna arambourgi Cappetta, 1970 do Miocénico de Loupian, mas algumas diferenças na face labial da coroa e na raíz são suficientes para as distinguir.

\section{CONCLUSÕES}

1. A distribuição dos Carcharhiniformes, que constituem a maioria (ca. de 40\%) dos táxones de seláceos representados nas jazidas de Santa Margarida, Esbarrondadoiro e Vale de Zebro, é a que se mostra na tabela1.

2. A repartição quantitativa dos táxones de Carcharhiniformes é muito desigual. A julgar pelo número de dentes (que não é possível extrapolar para números de indivíduos mas dá uma boa aproximação), há nítido predomínio de 4 formas, só uma identificada sem reserva ao nível da espécie, embora os géneros estejam bem caracterizados:

- Premontreia (Oxyscyllium) cf. dachiardi;

- Mustelus sp.;

- Paragaleus antunesi;

- e, sobretudo, Carcharhinus cf. perezi.

Quaisquer considerações de carácter ecológico ou outras têm de atender com maior peso às indicações que estas formas fornecem (v. Antunes, Balbino e Cappetta, 1999b: 119-121).

3. É interessante a raridade do tubarão-tigre, Galeocerdo, cuja decadência em mares europeus era já evidente. Ainda que atribuído à espécie miocénica comum, $G a$ leocerdo aduncus, está representado por uma forma muito evolucionada, aproximando-se do Galeocerdo cuvier, ainda actual e conhecido desde o Pliocénico. É a última ocorrência miocénica europeia conhecida, ainda que Leriche (1926: 439) cite a espécie na Bélgica, no Miocénico (Bolderiano e Anversiano) e Pliocénico (Diestiano e Scaldisiano). No entanto, dá poucos pormenores quanto à proveniência estratigráfica, indicada muito sumariamente; sem embargo do grande valor da vasta obra de Leriche, 


\begin{tabular}{|c|c|c|c|}
\hline Carcharhiniformes / Taxa & $N^{0}$ de espécimes / Number of specimens & $\sum$ & $\%$ \\
\hline Megascyliorhinus miocaenicus (Antunes e Jonet, 1970) & $1(\mathrm{SM}), 3(\mathrm{ESB})$ & 4 & 0.26 \\
\hline Premontreia (Oxyscyllium) cf. dachiardi (Lawley, 1876) & 48 (SM), 225 (ESB), 26 (VZ) & 299 & 19.09 \\
\hline Scyliorhinus joleaudi Cappetta, 1970 & $1(\mathrm{SM}), 10(\mathrm{ESB})$ & 11 & 0.70 \\
\hline Triakis cf. costamagnai Cappetta e Nolf, 1991 & $2(\mathrm{SM}), 1(\mathrm{ESB})$ & 3 & 0.19 \\
\hline Mustelus sp. & 23 (SM), 119 (ESB), 1 (VZ) & 143 & 9.13 \\
\hline Galeorhinus gonçalvesi Antunes, Balbino e Cappetta, 1999a & $2(\mathrm{SM}), 8(\mathrm{ESB}), 2(\mathrm{VZ})$ & 12 & 0.77 \\
\hline Paragaleus antunesi Balbino e Cappetta, 2000 & 96 (SM), 296 (ESB), 28 (VZ) & 420 & 26.82 \\
\hline Galeocerdo aduncus Agassiz, 1843 & $1(\mathrm{ESB})$ & 1 & 0.06 \\
\hline Rhizoprionodon sp. & $4(\mathrm{SM}), 14(\mathrm{ESB})$ & 18 & 1.15 \\
\hline Carcharhinus cf. leucas Valenciennes, 1839 & $10(\mathrm{ESB}), 4(\mathrm{VZ})$ & 14 & 0.89 \\
\hline Carcharhinus cf. plumbeus Nardo, 1827 & 7 (ESB), $9(\mathrm{VZ})$ & 16 & 1.02 \\
\hline Carcharhinus cf. perezi Poey, 1876 & 25 (SM), 380 (ESB), 160 (VZ) & 565 & 36.08 \\
\hline Sphyrna sp. 1 & $3(\mathrm{SM}), 14(\mathrm{ESB}), 4(\mathrm{VZ})$ & 21 & 1.34 \\
\hline Sphyrna sp. 2 & 9 (SM), 21 (ESB), 9 (VZ) & 39 & 2.49 \\
\hline TOTAL & 214 (SM), 1109 (ESB), 243 (VZ) & 1566 & 99.99 \\
\hline
\end{tabular}

Tabela 1. Repartição dos táxones de Carcharhiniformes nas jazidas de Santa Margarida (SM), Esbarrondadoiro (ESB) e Vale de Zebro (VZ). Formação de Esbarrondadoiro, Miocénico terminal (Messiniense), ca. 5.5 Ma.

Distribution of the Carcharhiniform taxa represented at Santa Margarida (SM), Esbarrondadoiro (ESB) and Vale de Zebro (VZ). Esbarrondadoiro Formation, uppermost Miocene (Messinian), ca. 5,5 Ma.

às vezes foram detectados erros de interpretação estratigráfica, como foi o caso da ocorrência no Miocénico de Carcharodon carcharias (v. Antunes, 1978).

4. Tendo em conta especialmente as características de representantes actuais semelhantes às formas predominantes, a repartição diferente dos Carcharhiniformes nas três jazidas (assim como a das outras ordens aí representadas) aponta, em conjunto com as características sedimentares, para áreas distintas do ponto de vista ecológico:

- Esbarrondadoiro indica meio relativamente mais profundo e águas pouco agitadas;

- Santa Margarida corresponde a uma área litoral e a mar agitado;

- Vale de Zebro, a parte interior de um golfo com fundos vasosos.

5. Do ponto de vista térmico, verificam-se ausências espectaculares de formas estenotérmicas termófilas, antes comuns, algumas abundantes:

- Orectolobidae (como Ginglymostoma, presente no Miocénico inferior e até o início do Miocénico médio de Lisboa);

- Negaprion, comum até o início do Miocénico médio, na mesma área e no Algarve;

- Hemipristis, escasso nos primeiros tempos do Miocénico superior (Tortoniano) mas frequente em níveis miocénicos mais antigos, nas mesmas áreas;

- a quase ausência de Galeocerdo, cuja repartição cronológica nas áreas consideradas é semelhante à de Hemipristis, escasseando na parte superior do Miocénico médio e no Tortoniano.
É de acrescentar outra constatação curiosa, corroborante da interpretação dada acima: a da total falta na Bacia de Alvalade de restos dos enormes crocodilos tipicamente termófilos Tomistoma lusitanica e Gavialis sp., comuns em facies semelhantes até o início do Miocénico médio, escassos mas ainda representados no Tortoniano da Península de Setúbal (Antunes, 1987, 1994).

6. Há elementos predominantemente de águas moderadamente quentes ou temperadas em Alvalade, frequentes na actualidade - Mustelus, Galeorhinus, Scyliorhinus, Triakis - enquanto que a frequência de Carcharhinus, género que esporadicamente ainda ocorre em Portugal, aponta para águas algo mais quentes do que as dos nossos dias, o que é corroborado talvez pela frequência de Paragaleus, e pela abundância e variedade das espécies de Dasyatis em relação à fauna actual em contraste com a raridade de Raja, mais próprio de águas temperadas e frias (Antunes, Balbino e Cappetta, 1999b:119-122).

7. Atendendo aos pontos 5 e 6 , é de concluir que reinavam no final do Miocénico e na Bacia de Alvalade condições caracterizadas por águas moderadamente quentes, menos quentes do que no Tortoniano, mais do que na actualidade.

8. A escassez de fauna pelágica e dos maiores predadores pelágicos, especialmente Isurus hastalis e Carcharocles megalodon, permite-nos afirmar estarmos perante um golfo relativamente estreito e não de uma fachada atlântica aberta. 
9. A diferença de faunas ictiológicas entre o Tortoniano de Lisboa e o Messiniano de Alvalade apontam no mesmo sentido: meio confinado em Alvalade, contrastando com uma situação de mar aberto no Tortoniano lisbonense. Reinavam condições de águas moderadamente quentes, menos do que no Tortoniano de Lisboa, mais do que na actualidade.

10. Um carácter de modernidade, ainda que a ser tomado com alguma reserva, comparativamente a faunas miocénicas consiste no carácter muito evoluído do Galeocerdo, já próximo de G. cuvier. Também os Carcharhinus da Bacia de Alvalade parecem, mesmo antes de estudo comparativo mais desenvolvido, corresponder a formas mais evolucionadas do que as do Tortoniano de Lisboa-Península de Setúbal.

\section{AGRADECIMENTOS}

Os autores exprimem os seus melhores agradecimentos às Instituições e pessoas que nos auxiliaram: Fundação para a Ciência e a Tecnologia e Projecto "POCTI/36531/PAL/2000 Studies on Portuguese Paleontology (Post - Paleozoic)" e Centro de Estudos Geológicos da Universidade Nova de Lisboa. Aos referees Henri-Charles Cappetta (Université de Montpellier II) e Jürgen Kriwet (University of Bristol), bem como ao Editor Rodolfo Gozalo Gutiérrez por sugestões úteis.

\section{BIBLIOGRAFIA}

Agassiz, L.1833-1844. Recherches sur les poissons fossiles. Neuchâtel, 5 vol., 1420 pp.

Alberdi, M. T., Antunes, M. T., Sondaar, P. Y. et Zbyszewski, G. 1978. Les Hipparion du Portugal. Ciências da Terra (UNL), 4, 129-156.

Antunes, M. T. 1978. Faunes ichthyologiques du Néogène supérieur d'Angola, leur âge, remarques sur le Pliocène marin en Afrique australe. Ciências da Terra (UNL), 4, 59-90.

Antunes, M. T. 1987. Affinities and taxinomical status of miocene longirostrine crocodilians from western Europe with remarks on phyllogeny, paleoecology and distribution. Comunicações dos Serviços Geológicos de Portugal, 73, 49-58.

Antunes, M. T. 1994. On Western Europe Miocene Gavials (Crocodylia)/ their Paleogeography, Migrations and Climatic significance. Comunicações do Instituto Geológico e Mineiro, 80, 57-69.

Antunes, M. T., Balbino, A. et Gaudant, J. 1995. Découverte du plus récent poisson Characiforme européen dans le Miocène terminal du Portugal. Comunicações do Instituto Geológico e Mineiro, 81, 79-84.

Antunes, M. T., Balbino, A. C. and Cappetta, H. C. 1999a. A new shark, Galeorhinus gonçalvesi (Triakidae, Carcharhiniformes) from the uppermost Miocene of Portugal. Tertiary Research, 19, 105-110.
Antunes, M. T., Balbino, A. C. e Cappetta, H. C. 1999b. Sélaciens du Miocène terminal du basin d'Alvalade (Portugal). Essai de synthèse. Ciências da Terra (UNL), 13, 115-129.

Antunes, M. T. et Jonet, S. 1970. Requins de 1'Helvétien supérieur et du Tortonien de Lisbonne. Revista da Faculdade de Ciências de Lisboa, 2a série, C, 16, 119-280.

Antunes, M. T. et Mein, P.1983. Petits mammifères de la fin du Miocène moyen dans les dépôts marins de Cerrado da Pedra, Alcácer do Sal. Comunicações dos Serviços Geológicos de Portugal, 69, 373-379.

Antunes, M. T., Mein, P. e Pais, J. 1986. Depósitos messinianos do Sul de Portugal, mamíferos (incluindo Rodentia e Lagomorpha) e idades K-Ar. Ciências da Terra (UNL), 8, 55-64.

Antunes, M. T. et Mein, P. 1989. Petits mammifères du Miocène terminal du bassin de Alvalade (Portugal); comparaisons avec des faunes de l'Espagne et du Maghreb. Bolletino della Società Paleontologica Italiana, 28, 161-170.

Antunes, M. T. et Mein, P. 1995. Nouvelles données sur les petits mammifères du Miocène terminal du Bassin de Alvalade, Portugal. Comunicações Instituto Geológico e Mineiro, 81, 85-96.

Antunes, M. T. and Pais, J.1993. The Neogene of Portugal. Ciências da Terra (UNL), 12, 7-22.

Arambourg, C. 1952. Les vertébrés fossiles des gisements de phosphates (Maroc- Algérie-Tunisie). Notes et Mémoires Services Geológique Maroc, 92, 1-372.

Balbino, A. Cáceres. 1995. Seláceos (Pisces) do Miocénico terminal da Bacia de Alvalade (Portugal)/ Sistemática, Ecologia, Paleoambientes, Comparação com faunas actuais. Dissertação de Doutoramento apresentada à Universidade de Évora, 200 pp. (inédito).

Balbino, A. C. and Cappetta, H. C. 2000. Paragaleus antunesi (Hemigaleidae, Carcharhiniformes) a new shark species from the latest Miocene of Portugal. Tertiary Research, 20, 1-6.

Blainville, H.M.D. 1816. Prodrome d'une distribution systématique du règne animal. Bulletin de la Société Philomatique, 8, 105-24.

Bonança, J.1887. Historia da Luzitania e da Iberia, desde os tempos primitivos ao estabelecimento definitivo do domínio romano. Lisboa, 1, 900 pp.

Budker, P. 1935. Description d'une genre nouveau de la famille des Carcharhinidae. Bulletin du Muséum national d' Histoire naturelle, $2^{\mathrm{e}}$ Ser., 7, 107-12.

Cappetta, H. C. 1970. Les Sélaciens du Miocène de la région de Montpellier. Palaeovertebrata, Mémoire extraordinaire, 1-139.

Cappetta, H. C. 1987. Mesozoic and Cenozoic Elasmobranchii Chondrichthyes II. Gustav Fischer Verlag, Stuttgart, 1-193.

Cappetta, H. C. 1992. Carcharhiniformes nouveaux (Chondrichthyes, Neoselachii) de l'Yprésien du bassin de Paris). Geobios, 25, 639-646.

Cappetta, H. C. et Nolf, D. 1981. Les sélaciens de l'Auversien de Ronquerolles (Eocène supérieur du bassin de Paris). Mededelingen Werkgroep Tertiair en Kwartair Geologie, 18, 87-107. 
Cappetta, H. C. et Nolf, D. 1991. Les Sélaciens du Pliocène inférieur de Le-Puget-sur-Argens (Sud-Est de la France). Palaeontographica, Abt. A, 218, 49-67.

Cappetta, H. C. and Ward, D. J. 1977. A new Eocene shark from the London Clay of Essex. Palaeontology, 20, 195-202.

Compagno, L. J. V. 1973. Interrelationships of living elasmobranchs. In: Interrelationships of fishes (Eds. P. H. Greenwood, R. S. Miles and C. Patterson). Zoological Journal of the Linnean Society, 53, Suppl. 1, 15-61.

Compagno, L. J. V. 1988. Sharks of the order Carcharhiniformes. Princeton University Press, Princeton, 1-486.

Dollfus,G., Cotter, J.C.B. et Gomes, J.P. 1904. Mollusques tertiaires du Portugal. Planches de Céphalopodes, Gasterópodes et Pélécypodes laissées par F.A. Pereira da Costa accompagnées d'une esquisse géologique. Memória, Serviços Geológicos de Portugal, 1-48.

Génault, B. 1993. Contribution à l'étude des Élasmobranches oligocènes du bassin de Paris/Découverte de deux Horizons à Élasmobranches dans le Stampien (Sables de Fontainebleau) de la feuille géologique de Chartres. Cossmanniana, Paris, 2, 13-36.

Jonet, S. 1978. Le Tortonien supérieur (T VII-b) des environs de Fonte da Telha (Peninsule de Setúbal) et ses faunes. Comunicações dos Serviços Geológicos de Portugal, 63, 13-51.

Jonet, S. 1996. Notes d'Ichthyologie Miocène portugaise IILes Carcharhinidae. Boletim do Museu e Laboratório Mineralógico e Geológico da Faculdade de Ciências de Lisboa, 10, 65-88.

Lawley, R., 1876. Nuovi studi sopra ai pesci ed altri vertebrati fossili Toscani. Florence, $122 \mathrm{pp}$.

Leriche, M. 1926. Les Poissons Néogènes de la Belgique. Mémoires du Musée Royal d'Histoire Naturelle de Belgique, Mémoire, 32, 365-472.

Leriche, M., 1942. Contribution à l'étude des faunes ichthyologiques marines des terrains tertiaires de la plaine côtière atlantique et du centre des Etats-Unis. Mémoires de la Société Géologique de France, n.s., 20, 110 pp.

Link, H. F. 1789. Versuch Einer Eintheilung der Fische nach den Zähnen. Neueste Physikalisches Naturgeschichte, 6 , 28-38.

Müller,J. und Henle, F.G.J. 1837. Gattungen der Haifische und Rochen, nach ihrer Arbeit: Ueber die Naturgeschichte der Knorpelfische. Berichte Kaiserlich Preussens Akademie der Wissenschaften, 2, 111-8.

Nardo, G.D. 1827. Prodromus observationum et disquisitionum Adriaticae ichthyologiae. Giornale Fisica Chimica Storia Natural Medica Arti, 22-40.

Noubhani, A. 1993. Les Sélaciens des bassins à phosphate du Maroc (Maastrichtien-Lutetien)/Systématique-Biostratigraphie-Evolution et dynamique des faunes. Thèse, $\mathrm{V}$. 1 e V.2. Montpellier, 338 pp. (inédito).

Noubhani, A. et Cappetta, H. 1997. Les Orectolobiformes, Carcharhiniformes et Myliobatiformes (Elasmobranchii, Neoselachii) des bassins à phosphate du Maroc (Maastrichtien-Lutétien basal) : Systématique, biostratigraphie, évolution et dynamique des faunes. Palaeo-Icthyologica, 8, 1-327.

Poey, F., 1876. Enumeratio piscium cubensium. Anales de la Sociedad Española de Historia Natural, 5, 177-218.

Rafinesque, C. S. 1810. Caratteri di alcuni nuovi generi e nuove specie di animali e piante della Sicillia. Palermo, $105 \mathrm{pp}$.

Serralheiro, A. M. Romão. 1954. Contribuição para o conhecimento da fauna ictiológica do Miocénico marinho de Portugal. Revista da Faculdade de Ciências da Universidade de Lisboa, 4, 39-119.

Whitley, G.P., 1929. Additions to the check-list of the fishes of New South Wales. No.2. Australian Zoology, 5, 353-7.

Zbyszewski, G. e Almeida, F. M. 1950. Os peixes miocénicos portugueses. Comunicações dos Serviços Geológicos de Portugal, 31, 1-108.

Manuscrito recibido: 20 de febrero, 2003 Manuscrito aceptado: 5 de noviembre, 2003 